\title{
Coutinho's Method for the Altitude
}

\author{
António Costa Canas1,2, Magda Ramires Marabujo3, Teresa Sousa1,4 \\ 1Escola Naval and CINAV, Base Naval de Lisboa - Alfeite 2810-001 Almada, Portugal \\ ${ }_{2} \mathrm{CH}-$ ULisboa, Universidade de Lisboa, 1600-214 Lisboa, Portugal \\ 3Escola Naval, Base Naval de Lisboa - Alfeite 2810-001 Almada, Portugal \\ 4Centro de Matemática e Aplicações (CMA), FCT-UNL, Campus de Caparica, 2829-516 Caparica, \\ Portugal \\ (E-mail: teresa.maria.sousa@marinha.pt)
}

\begin{abstract}
In the first South Atlantic Aerial Crossing, by Gago Coutinho and Sacadura Cabral in 1922, several methods of astronomical maritime navigation were used with adaptions to aerial navigation. In order to apply these methods, the navigator needed to know the approximate aircraft's altitude so that the position of the aircraft could be determined. The instrument available at that time, the altimeter, did not give reliable values for the altitude. Therefore, Gago Coutinho had to devise a method that allowed the navigator to determine the altitude quickly and efficiently.

Coutinho's method is based on a mathematical and geometrical procedure. In this paper, we study in detail Coutinho's method to determine the altitude. The paper contains various diagrams to better understand all the deductions and calculations. We will also present a real example of how this method would be used during the flight.
\end{abstract}

KEYWORDS: Altitude, Aviation, Gago Coutinho, History, Navigation

\section{INTRODUCTION.}

"Navigation is the means whereby the mariner or aviator ascertains his position on the surface of the earth, and determines the exact direction in which he must head his craft in order to reach its destination." (Brown, 1920, P.93)

Until 1922, there were no scientific methods of astronomical navigation that permitted an aircraft to fly out of sight of land safely. Its necessity was still reduced, since most of the flights that were made were of short distance and with the sight of land. In this situation the navigator could check the progress of the aircraft towards the desired destination only by observation of landmarks and the use of very rudimentary instruments. Although such equipment was capable of providing basic data such as direction (compass), distance (speedometer) and altitude (altimeter), this information was not sufficient to achieve the objective of flying long distances over the sea. For this reason, it was essential to develop air navigation procedures that allowed an aircraft to fly out of sight of land safely. The first methods developed in the beginnings of aerial navigation were inspired in the procedures used in maritime navigation. 
"In short journeys over land by aeroplane or airship the duties of a navigator are light, so long as he can see the ground and check his progress towards the objective by observation and a suitable map. But for long distance flights, especially over the ocean and under circumstances whereby the ground cannot be seen, the navigator of the air borrows much from the navigator of the sea." (Brown, 1920, P.94)

Nevertheless, Brown highlights the fact that there are also some distinctions between air and sea navigation, resulting from differences in the characteristics of the fluids in which each type of navigation was carried out, namely water, or air.

"The chief differences between the navigation of aircraft and the navigation of seacraft are occasioned by:

(a) The vastly greater speed of aircraft, necessitating more frequent observations and quicker methods of calculation.

(b) The serious drift caused by the wind. This may take aircraft anything up to forty or more miles off the course in each hour's flying, according to the direction and strength of the wind. In cloudy weather, or at night, a change in the wind can alter the drift without the knowledge of the navigator. Hence, special precautions must be taken to observe the drift at all possible times.

(c) The absence of need for extreme accuracy of navigation in the air, since a ten or even twenty mile error from the destination in a long journey is permissible. Another favorable point is that rocks, reefs and shoals need not be avoided. This permits the aerial navigator to use short cuts and approximations in calculation, which would be criminal in marine navigation." (Brown, 1920, P.95)

In 1919, Hawker and Grieve attempted to cross the Atlantic Ocean, but unfortunately, they were obliged to ditch their plane at sea. From their experience, they concluded that accurate methods of aerial navigation needed to be developed in order to guarantee the success of long flights over the ocean.

"[...] in a flight such that which we attempted, a non-stop journey of over 2000 miles, accurate navigation is of absolutely prime importance, [...] (Hawker and Grieve, 1919, P.60)

In 1922, Gago Coutinho and Sacadura Cabral, two officers of the Portuguese Navy, completed, for the first time, the First Air Crossing of the South Atlantic from Lisbon to Rio de Janeiro. This crossing was different from that of Hawker and Grieve in that the latter only depended on the navigator's ability to reach the west coast of Ireland but Coutinho and Cabral needed to reach Saint Paul's Rocks, a tiny point in the immensity of the Atlantic Ocean. 
"The highest point of St. Paul's Rocks is sixty feet above water; for the most part they are only twenty feet in height, and they are less than a hundred yards long. To hit this tiny spot after flying $11 \frac{1}{2}$ hours over the open Atlantic is the greatest example of air navigation yet performed." (Jones, 1931, P.255)

The success of this flight was due to the fact that Coutinho and Cabral conceived and developed the first scientific methods of aerial navigation:

"This crossing, having been done in the most accurate and scientific manner, is an unparalleled stride towards the practical solution of the problems concerning the navigation through the air." (Anonymous, 1922, P.361)

The solutions devised by the two officers include the invention of two instruments, namely the Path Corrector and the Precision Sextant, a sextant with an artificial horizon. Besides these instruments, Coutinho also developed the first methods of aerial astronomic navigation, which include a method to determine the aircraft's position as well as the altitude. We shall describe these solutions briefly.

The determination of the direction and speed of the wind was a problem that needed to be solved so that the navigator could estimate the drift caused by the wind. To deal with this difficulty, Coutinho and Sacadura invented an instrument, called the Path Corrector, that enabled the navigator to determine the direction and speed of the wind. Furthermore, the Path Corrector could also be used to determine the new direction of the aircraft in order to compensate for the wind drift. For a detailed study of the construction and use of the Path Corrector, the reader can see Coutinho (1927) and Canas et al. (2019).

"Between the instruments used for the purpose the Course Corrector must have a prominent place, because, the perfectly accurate Dead Reckoning can be done with it." (Anonymous, 1922, P.361)

The sextant used in maritime navigation could not be used in aerial navigation due to the difficulty of the definition of the sea horizon at a normal flight altitude. Nevertheless, Coutinho believed that its accuracy would be essential to determine the position of the aircraft during the flight. Therefore, he developed a new model of sextant with an artificial horizon, called a Precision Sextant, that could be used to measure the height of a star without the need of the sea horizon. For details about the precision sextant, the reader is referred to Coutinho (1927) and Pereira (2015).

"The sextant, used for observations in the air, with its own artificial horizon, makes it practical to estimate the altitudes with the accuracy required in aerial navigation, in cases where it is impossible or inconvenient to descend in order to observe on the sea horizon;" (Anonymous, 1922, P.361)

An important achievement accomplished by Coutinho and Sacadura was the development of methods of Astronomic Navigation that could be used effectively on board of aircrafts. 
"The use of points of reference through the line of the intended crossing, and the able and skill modifications of the formulae of Nautical Astronomy, by which the observer may, before starting, prepare the greatest part of his calculations, in this way leaving only another quite material part, to be done in the air; are the two conceptions by which the Astronomical Navigation with a sextant, can be done in the air with accuracy and comfort, as happens on board ship, together with the quickness exacted in virtue of the great speed of aeroplanes." (Anonymous, 1922, P.361-362)

A crucial aspect for the success and effectiveness of the methods of Astronomic Navigation developed and used by Coutinho and Sacadura was the determination of the aircraft's altitude.

"The calculation of the position, through the observations of the stars, requires the approximate knowledge of our altitude [...]."1 (Coutinho, 1923, P.10)

To solve this problem, Coutinho developed a geometrical procedure that allowed the navigator to quickly determine the altitude during the flight. For this, the navigator would have to measure the aircraft's shadow on the sea surface and then with the help of a table that had been pre-calculated before the flight he would determine the aircraft's altitude easily.

"[...] the shadow of the aeroplane on the surface of the sea is sufficiently clear for measuring with the sextant or telemetric binocle. Evidently, one must, $[\ldots]$ have a small table calculated with the length of the wings of the aeroplane to give the coefficient $\mathrm{K}$ in the formula

$$
\text { height }=K \text { cot. angle of shadow }
$$

a formula which gives the height with an error of a few feet, equivalent to an error of less than a minute of depression." (Coutinho and Cabral, 1922, P.374)

In section 3, we study in detail Coutinho's geometrical procedure to determine the aircraft's altitude 2 and how to determine the coefficient $\mathrm{K}$ in the above formula. Having determined the mathematical expression to calculate the coefficient $\mathrm{K}$, we will then explain how Coutinho calculated in advanced the table he referred to. We will include various diagrams to understand

1 "O cálculo da posição, por meio de observações dos astros, exige o conhecimento aproximado da nossa altitude [...]" (Coutinho, 1923, P.10)

2 The vertical (geometrical) distance of the aircraft from the Mean Sea Level (MSL) is called True Altitude. Altitude (in current air navigation) is a barometric measure, it is the vertical distance in ISA (International Standard Atmosphere) between the static pressure of the isobaric surface the aircraft is flying and the QNH pressure of the isobaric surface at the MSL, at a certain temperature. True Altitude is different from Altitude by a correction which depends on the real atmosphere deviation from ISA pressure and temperature. Coutinho's method measures the True Altitude. However, in the early days of air navigation there was no distinction between Altitude and True Altitude. Therefore, we shall use the term Altitude instead of True Altitude throughout the paper. 
better the mathematical construction that underlies the procedure. We conclude the paper with an example of how the procedure would have been used during the flight.

2. THE NEED TO DETERMINE THE AIRCRAFT'S ALTITUDE IN AERIAL NAVIGATION. The first scientific methods of aerial navigation were inspired by the techniques used in maritime navigation. However, aerial navigation dealt with specific problems that did not arise in maritime navigation. One of those problems was the need to determine the aircraft's altitude.

"Then again, height has to be allowed for. On board a ship this remains pretty constant, so that corrections are easily made, whereas in an aeroplane, as in our case, one's height can vary within an hour or two or less from 15,000 feet to 1000 feet. Height is taken from the barometer, but as the barometer reading alters according to atmospheric conditions as well as being affected by height, a very big error can enter into this part of the calculation." (Hawker and Grieve, 1919, P.61-62)

An alternative would be the use of the altimeter. However, the readings from the altimeter were also not reliable.

"Hence an altimeter will commonly read 21,000 feet when the height is really 20,000 feet." (Wimperis, 1920, P.40-41)

As we can see, the altimeter was not reliable and efficient for aerial navigation. Hence, determining the altitude of the aircraft was a new problem that needed to be solved.

"Until we know our exact height above the sea we cannot plot our exact position" (Maitland, 1920, P.44)

Knowledge of the exact altitude of the aircraft was important when determining the exact position of the aircraft. The exact position of the aircraft could be known using methods of astronomic navigation, therefore the knowledge of the aircraft's altitude was important in order to account for corrections related to dip.

"Dip Correction. - The second correction to be applied is the correction for the dip of the horizon. Viewed from an airplane, the horizon is below the eye. The greater the height of the airplane above the water, the greater is the angle of the horizon below a horizontal line through the observer's eye. This angle is called the angle of dip." (Jones, 1931, P.130-131)

Therefore, it was extremely necessary to develop an efficient and accurate procedure to determine the altitude of the aircraft. Jones describes a method to determine the altitude. 
"One method of finding the altitude above the water was to drop plaster of Paris eggs and count time from the instant they were released until they could be seen shattering on the water. At night a searchlight with a conical beam of light was pointed vertically downwards. The size of the circle of light on the water was dependent upon the altitude, so that by measuring the diameter of this circle by means of stadia wires in a telescope mounted alongside the searchlight the altitude could be obtained." (Jones, 1931, P.40)

The latter method and Coutinho's method are based on the same principle. However, Coutinho's method can only be used during the day while the second method described above can only be used at night. Coutinho's method will be described in detail in section 3 .

Jones's book was written in 1931. Therefore, some of the methods described in the book might have been developed after Coutinho and Sacadura's flight (1922) or even be developed independently by other navigators. Furthermore, Jones does not describe the flights where the methods were used, although he mentions that they were practical and used on actual flights.

"The methods described in this book are practical; they have all been used on actual flights." (Jones, 1931, P.vii)

Another method that we found in the literature was the method used by the H.M. Airship R34 in their successful east-to-west Atlantic crossing in 1919. Very briefly, the method consisted of measuring the angle shadow of the airship on the sea surface and with the knowledge of that angle they would determine the value of the altitude.

"Scott works out our height above the water in the following way -

The airship is throwing a very dark shadow on the surface of the sea on starboard side - almost immediately underneath the ship. By taking with a sextant the angle subtended by length of the shadow, and knowing the length of the shadow to be 640 feet, he gets the true height. In this case the height works out at 2100 feet, whilst the aneroid gives us only 1200 feet - a variation of 900 feet." (Maitland, 1920, P.44)

Unfortunately, they do not explain how their method works, although they mention later in the text that the method is simple and reliable.

"The sun is high, so Cooke is able to get good idea of any barometric changes by observing the angle the ship's shadow on the water subtends with a sextant, thus calculating the distance of the shadow from the observer, and comparing with height recorded in the altimeter. This is only possible at low altitudes, i.e. about 1500 feet. (It sounds a bit complicated, but is quite effective!)" (Maitland, 1920, P.104) 
Coutinho also faced the same problem of determining the altitude. Therefore, he had to conceive a solution to this problem that could be used during the flight effectively. His method is similar to that used in the H.M. Airship R34 since it is based on the measurement of the plane's wingspan shadow at the sea surface. In the report of the 1923 South Atlantic crossing Coutinho writes

"[...] the approximate knowledge of our altitude, could be concluded from the Aneroid, or from the observation of the apparent shadow over the sea, of the wings of the plane, whose wingspan was known, for which we had calculated special small tables, entered the height of the sun, and which gave us a coefficient to be multiplied by the cotangent of the angle of the shadow, measured by the sextant or telemetric binocle."3 (Coutinho, 1923, P.10)

In the next section, we study in detail Coutinho's method to determine the altitude during the flight. His procedure relies on a geometrical and mathematical procedure to determine a specific constant $K$ that would be multiplied by the cotangent of the angle of the plane's wingspan shadow at the sea surface. Our study of the mathematical construction will be complemented with numerous diagrams and pictures so that the reader can follow the construction easily.

\section{COUTINHO'S GEOMETRICAL METHOD FOR THE AIRCRAFT'S} ALTITUDE. One of the problems that early aerial navigation had was the determination of the altitude in order to account for dip correction, necessary to determine the exact position of the aircraft. Therefore, it was necessary to find a way to determine the flight altitude as accurately as possible. As we have seen before, the altitude could be obtained using the value of the atmospheric pressure given by the barometer. However, this result would not be the most accurate and would introduce errors in the calculations that could compromise the success of the trip. Therefore, Coutinho needed to find a good solution to solve this problem.

"With clear sky, and with the Sun at an altitude of more than 30 degrees, the shadow of the aeroplane on the surface of the sea is sufficiently clear to be measured using the sextant or the telemetric binocle. Evidently, one must, as we did for Lusitania, have a small table, calculated with the length of the wings of the aeroplane to give the coefficient $\mathrm{K}$ in the formula:

$$
\text { height }=K \text { cot. angle of shadow }
$$

a formula which gives the height with an error of a few feet, equivalent to an error of less than a minute of depression." (Coutinho and Cabral, 1922, P.374)

\footnotetext{
3 “...o conhecimento aproximado da nossa altitude, a qual se poderá concluir do Aneroide, ou da observação da sombra, aparente sobre o mar, das asas do avião, cuja envergadura era conhecida, para o que levávamos calculadas pequenas tabelas especiaes, em que se entrava com a altura do sol, e que nos davam um coeficiente a multiplicar pela cotangente do angulo da sombra, medido a sextante ou a óculo telemétrico." (Coutinho, 1923, P.10)
} 
First, we have to observe that Coutinho is perfectly aware that this formula is not exact, however, as he states the error is sufficiently small and can be ignored. Secondly, note that Coutinho states that in order to measure the plane's wingspan shadow at the sea surface, the Sun's height must be at least at $30^{\circ}$. This requirement is essential, in fact, if the Sun's height is less than $30^{\circ}$ then the plane's shadow is stretched and projected far way, making it extremely hard to make accurate measurements in this case. Another important requirement is that the Sun's must be at the aircraft's beam, so in order to make this measurement, Coutinho had to steer the aircraft so that the Sun is at its beam.

In the rest of this section, we will explain in detail how Coutinho arrived at equation (1) and how this equation was used to determine the altitude. We start with a simple theoretical example. Let us observe the situation presented in Figure 1.

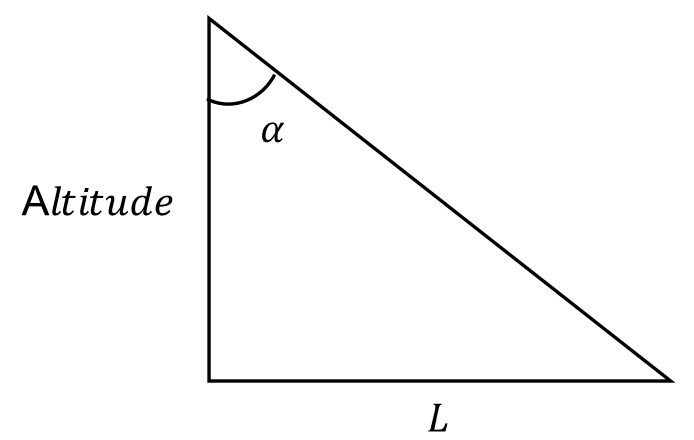

Figure 1: Theoretical example to determine the Altitude

In this case, we have

$$
\tan \alpha=\frac{L}{\text { Altitude }} \Leftrightarrow \text { Altitude }=\frac{L}{\tan \alpha} \Leftrightarrow \text { Altitude }=L \cot \alpha
$$

Therefore, by knowing the angle $\alpha$ and $L$, we can easily determine the altitude. However, this is not the situation that we want to study, rather a theoretical example that illustrates the problem of determining the altitude of an airplane in flight. To solve this problem, Coutinho developed an easy method, that gives the airplane altitude with an error of a few meters. Furthermore, Coutinho's procedure was quickly performed during the flight which is crucial in aerial navigation. In the rest of this section, we will study in detail how Coutinho arrived at his solution for determining the altitude during the flight and we will conclude with a real example.

For sake of simplicity, we will start by considering the simplest case and then proceed to the general case. Let us start with the case when the Sun's height is exactly $90^{\circ}$, that is, the Sun is vertical relative to the aircraft. Let $s_{h}$ denote the Sun's height, $e$ the wingspan of the biplane and let $\alpha$ denote the angle, measured with a sextant, of the biplane's shadow at the sea surface. Finally, let $s$ denote the length of the biplane's wingspan shadow on the sea surface. In this particular situation, since $s_{h}=90^{\circ}$ we clearly have $s=e$. (see Figure 2 ) 


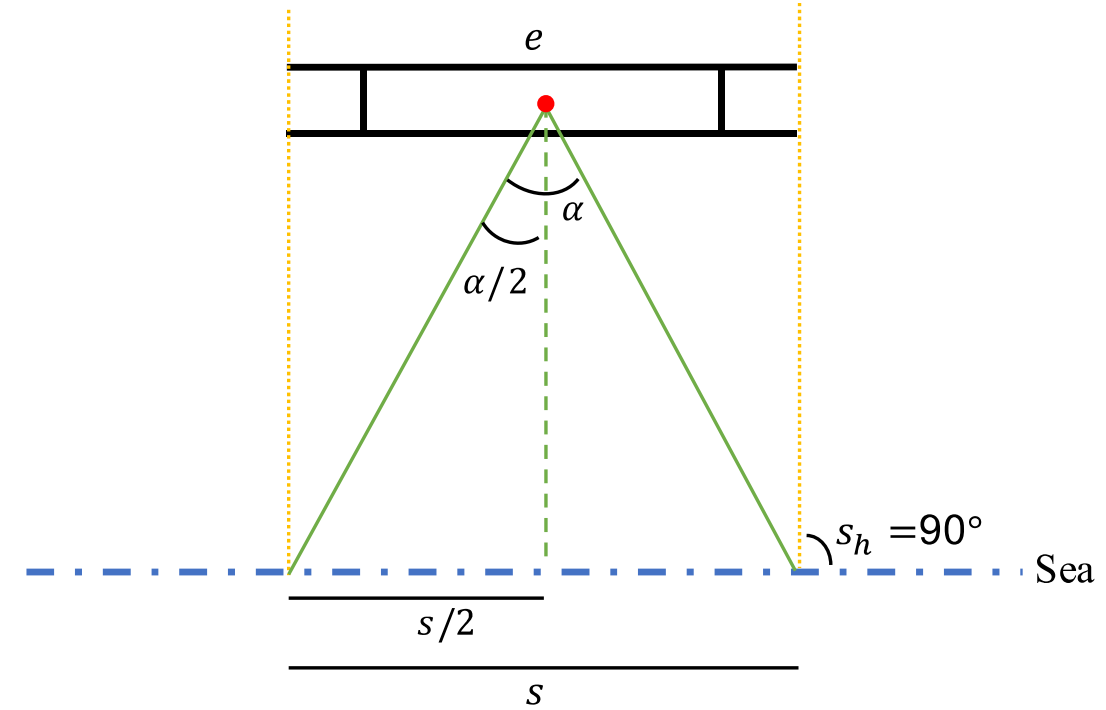

Figure 2: Geometrical scheme to determine the altitude with the Sun's height at exactly $90^{\circ}$

In this case, we have

$$
\text { Altitude }=\frac{s}{2} \cot \left(\frac{\alpha}{2}\right)
$$

Since the previous situation only occurs when the Sun's declination is equal to the place's latitude, which only happens in inter-tropical regions, Gago Coutinho needed to develop a procedure to determine the altitude that could be used at any given situation, requiring only that the Sun's height is at least $30^{\circ}$. As was noted before, Coutinho will use equation (1)

$$
\text { Altitude }=K \cot (\text { angle of shadow) }
$$

where $K$ is a coefficient that will be listed in a table. We will now explain how the coefficient $K$ is calculated.

Coutinho's aircraft was a biplane that is, an airplane with two main wings, one above the other and supported by struts. Thus, it was necessary to calculate the total length of the biplane's shadow on the surface of the sea. The vertical distance between the two wings will increase the length of the biplane's shadow on the sea surface by a quantity that will depend on the Sun's height. (see Figure 3) Therefore, we first need to determine how the vertical distance between the wings will increment the value of $s$. Recall that $s$ denotes the length of the biplane's wingspan shadow on the sea surface. Let $P$ denote the height between the two wings and let $x$ denote the quantity that we need to add to the length of the wingspan to determine the length of the biplane's shadow at the sea surface. That is,

$$
s=e+x
$$

where,

$$
x=P \cot \left(s_{h}\right)
$$




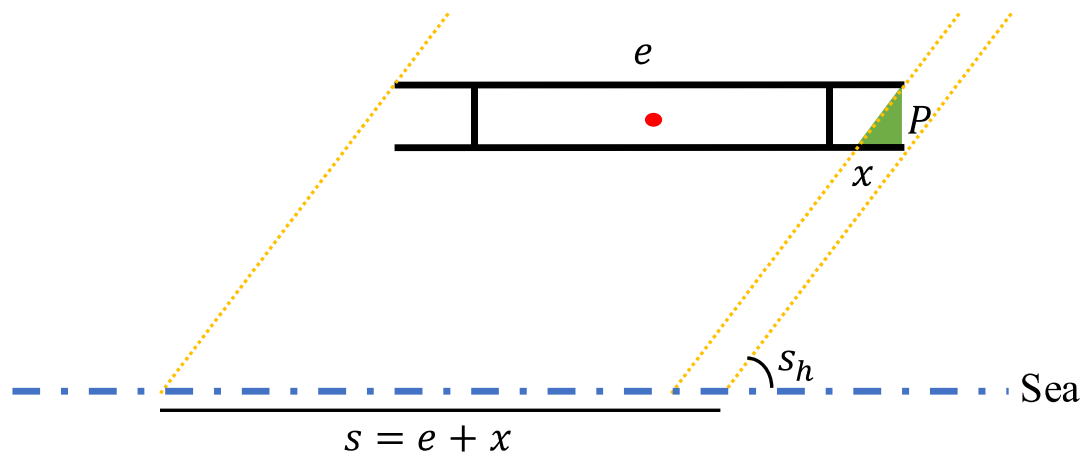

Figure 3: Scheme explaining how the Sun's height affects the length of the biplane's shadow on the sea surface

After determining how the height between the biplane wings will affect the dimension of its shadow on the sea surface, we will now proceed with the detailed explanation of Coutinho's method to determine the altitude. We recommend the reader to follow the diagram in Figure 4.

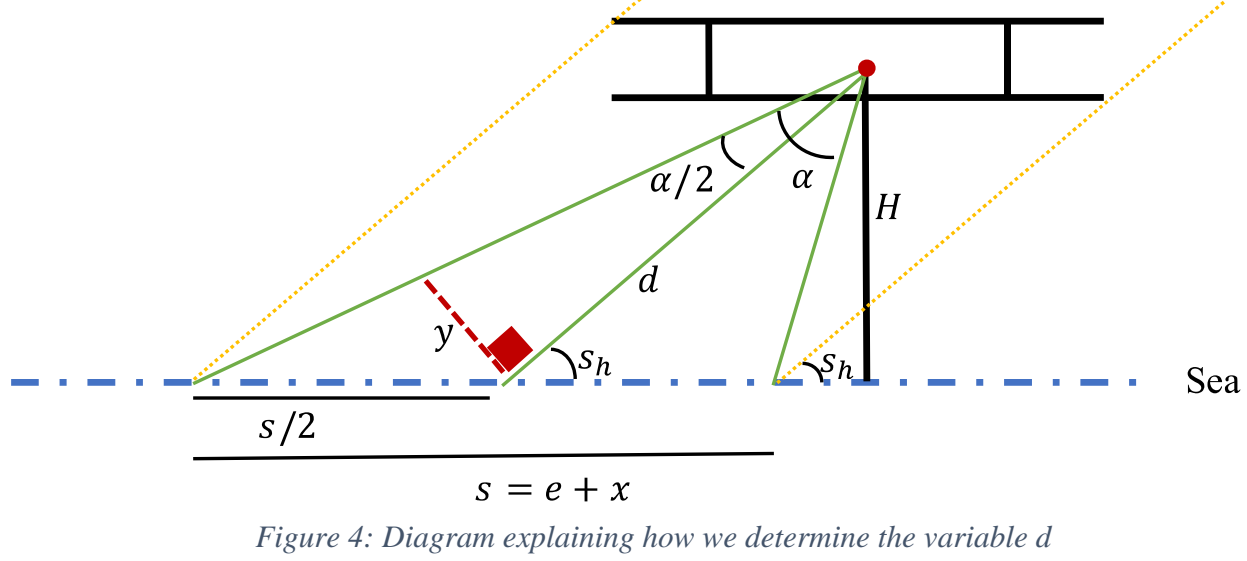

Recall that the objective is to determine the value of the altitude, here denoted by $H$. However, as it was noted before,

$$
\mathrm{H}=K \cot \text { (angle of shadow) }
$$

where $K$ is a coefficient that will depend only on known values, such as the Sun's height, the wingspan of the biplane and the height between the two wings. We will now present a detailed explanation on how Coutinho determined the value of the coefficient $K$. We will first determine the distance $d$. Consider the right triangle with right sides $y, d$ and angle $\alpha / 2$. To be absolutely precise, the measure of the angle is not exactly $\alpha / 2$, as it can be easily seen in the diagram depicted in Figure 4, nevertheless, for simplicity and without any effect on the calculation we can assume the measure of the angle is exactly $\alpha / 2$. We have,

$$
d=y \cot \left(\frac{\alpha}{2}\right)
$$

The value of $\alpha$ will be at most $14^{\circ}$. This upper bound was deduced by the authors from a planar model of the problem, i. e., not considering the effect of the altitude. In fact, for a fixed altitude we can easily see that the largest value of $\alpha$ is attained when the Sun's height is exactly $90^{\circ}$. 
Furthermore, if the altitude increases then the value of $\alpha$ will decrease. Coutinho's observations were made at an altitude of around 90 meters, for which the value of $\alpha$ will be at most $14^{\circ}$.

"The best plan, when more reliable observations are desired, is to lower the aeroplane till the line of the sea horizon becomes sufficiently clear (a height of $300 \mathrm{ft}$. generally ensuring this), and to make observations upon it, [...]" (Coutinho and Cabral, 1922, P.373)

Using simple trigonometric formulas, we can easily deduce that

$$
2 \cot (\alpha)=\cot \left(\frac{\alpha}{2}\right)\left[1-\tan ^{2}\left(\frac{\alpha}{2}\right)\right]
$$

Since $\alpha \leq 14^{\circ}$ we conclude that the term $\left[1-\tan ^{2}\left(\frac{\alpha}{2}\right)\right]$ is close to 1 , that is, in this case, we have $\cot \left(\frac{\alpha}{2}\right) \approx 2 \cot (\alpha)$. Therefore, it follows that

$$
d=y \cot \left(\frac{\alpha}{2}\right) \approx 2 y \cot (\alpha)
$$

Our next step will be to determine the value of $y$.
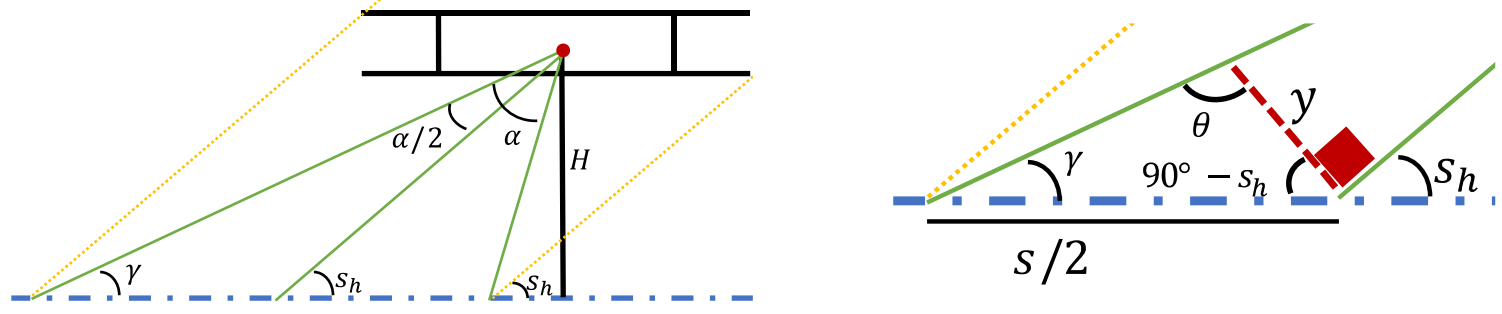

Figure 5: Diagram to determine the angle $\gamma($ left) and the variable $y$ (right)

Since the sum of the measures of the interior angles of a triangle equals $180^{\circ}$, we must have $\gamma=s_{h}-\alpha / 2$, where $\gamma$ is the angle marked in Figure 5 (left) and $\theta=90^{\circ}+\alpha / 2$, where $\theta$ is the angle marked in Figure 5 (right). Because the value of $\alpha$ is small, we can approximate $\theta$ by a right angle, therefore we have

$$
\cos \left(90^{\circ}-s_{h}\right)=\frac{y}{\frac{s}{2}} \Leftrightarrow y=\frac{s}{2} \cos \left(90^{\circ}-s_{h}\right) \Leftrightarrow y=\frac{s}{2} \sin s_{h}
$$

Recall that our aim was to determine the distance $d$. In fact, by using all the results we have obtained so far, we have

$$
\begin{aligned}
& d=y \cot \left(\frac{\alpha}{2}\right) \quad \text { (by equation (7)) } \\
& d \approx 2 y \cot (\alpha) \quad(\text { by equation }(9)) \\
& d \approx 2 \frac{s}{2} \sin \left(s_{h}\right) \cot (\alpha)=s \sin \left(s_{h}\right) \cot (\alpha) \quad \text { (by equation (10)) }
\end{aligned}
$$




$$
d \approx\left(e+P \cot \left(s_{h}\right)\right) \sin \left(s_{h}\right) \cot (\alpha) \quad \text { (by equations (4) and (5)) }
$$

Therefore,

$$
d \approx\left(e \sin \left(s_{h}\right)+P \cos \left(s_{h}\right)\right) \cot (\alpha)
$$

To conclude, consider the right triangle with side $H$ and angle $s_{h}$ as highlighted in Figure 6.

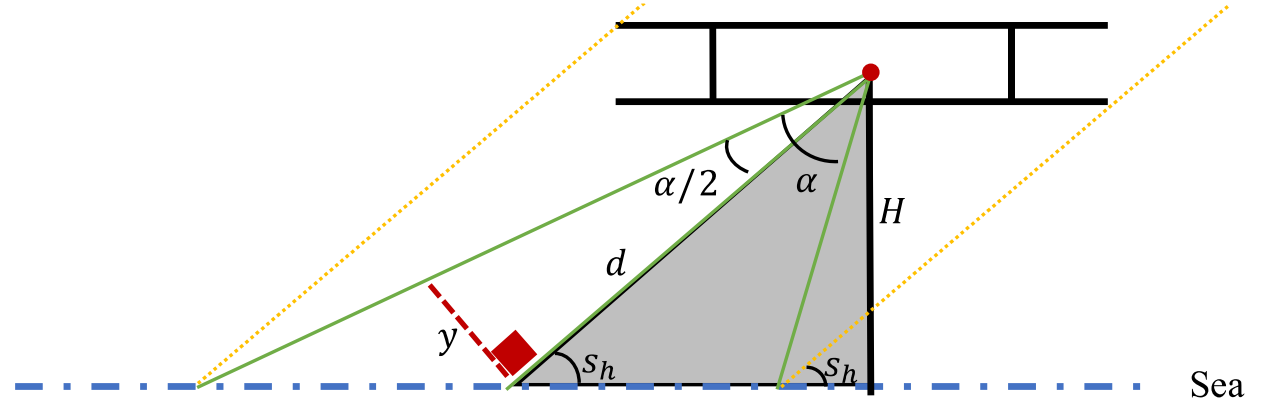

Figure 6: Diagram of the triangle to find the variable $H$

In this case, we have

$$
\sin \left(s_{h}\right)=\frac{H}{d}
$$

That is,

$$
\left.H=d \sin s_{h}\right)
$$

Therefore,

$$
\begin{aligned}
H & \approx\left(e \sin \left(s_{h}\right)+P \cos \left(s_{h}\right)\right) \cot (\alpha) \sin \left(s_{h}\right) \quad(\text { by equation }(10)) \\
& \approx\left(e \sin ^{2}\left(s_{h}\right)+P \cos \left(s_{h}\right) \sin \left(s_{h}\right)\right) \cot (\alpha)
\end{aligned}
$$

Thus, by letting

$$
K=e \sin ^{2}\left(s_{h}\right)+P \cos \left(s_{h}\right) \sin \left(s_{h}\right)
$$

we have

$$
H=K \cot (\alpha)
$$

as required.

Note that the coefficient $K$ depends only on known values, such as the Sun's height, the wingspan of the biplane and the height between the two wings, denoted by $s_{h}, e$ and $P$, respectively. Observe that $e$ and $P$ are fixed values for a given aircraft, in fact, in Coutinho's biplane, we have $e=19.2$ meters and $P=1.6$ meters. With this deduction for the coefficient $K$ Coutinho constructed a table as follows. In the left-hand side, we have the Sun's height $s_{h}$, varying from $90^{\circ}$ to $20^{\circ}$ and on the 
right-hand side we have the values of $\log K$ calculated using formula (14). All logarithms considered here are base 10 logarithms. (see Figure 7)

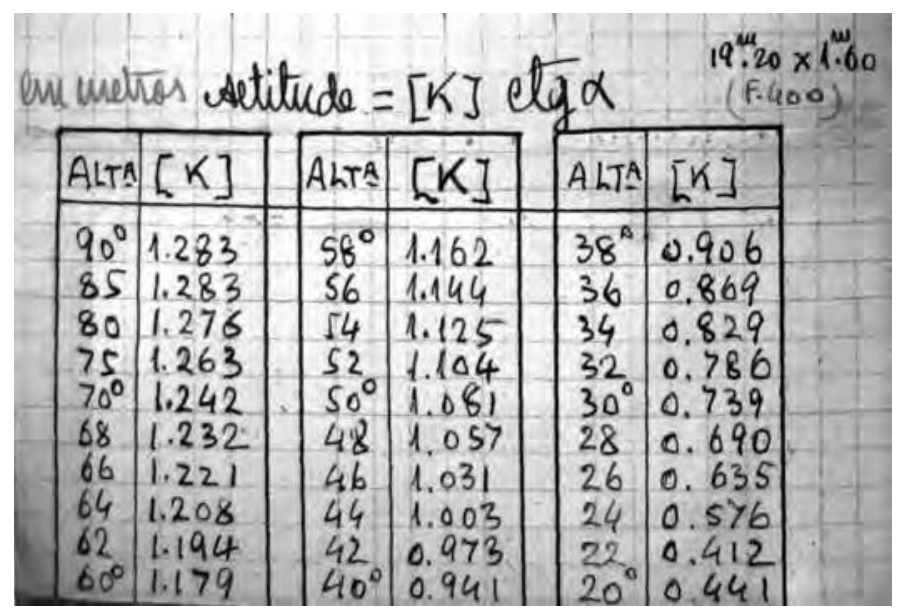

Figure 7: Gago Coutinho's table to determine the altitude during the flight (Font: Pereira, 2015, P.312)

We will conclude this section with a practical example of how Coutinho determined the altitude during the flight. Suppose that at the time of the measurement the Sun's height is $S_{h}=50^{\circ}$ and $\alpha=7^{\circ}$. Then, by equation (14) we have

$$
\begin{aligned}
\log K & \left.=\log \left(e \sin ^{2}\left(s_{h}\right)+P \cos \left(s_{h}\right) \sin \left(s_{h}\right)\right) e \sin ^{2}\left(s_{h}\right)\right) \\
& =\log \left(19.2 \sin ^{2}\left(50^{\circ}\right)+1.6 \cos \left(50^{\circ}\right) \sin \left(50^{\circ}\right)\right)=1.081162
\end{aligned}
$$

Observe that this is exactly the value that appears on the table in Figure 7 immediately to the right of $50^{\circ}$. Having the value for $\log K$ Coutinho would consult the book Table de Logarithmes, $J$. Hoüel to obtain the value for $\log (\cot \alpha)$. In this particular case, $\log \left(\cot \left(7^{\circ}\right)\right)=0.91086$. (See Figure 8) Thus,

$$
\log H=\log K+\log (\cot (\alpha))=1.992
$$

This implies that

$$
H=10^{1.992}
$$

Finally, we need to find the value of $10^{1.992}$. This value can also be found at Hoüel's tables. The value of $H$ is between 10 and 100, closer to 100 than to 10. Thus, searching the value at Hoüel's tables, one has to look for numbers on the table between 10 and 100 that best approximate 992, in this particular case the numbers are 98 and 99 (See Figure 9). Therefore, we conclude that the value of $H$ would be between 98 and 99 meters, that is, the aircraft's altitude would be approximately 98 meters. 


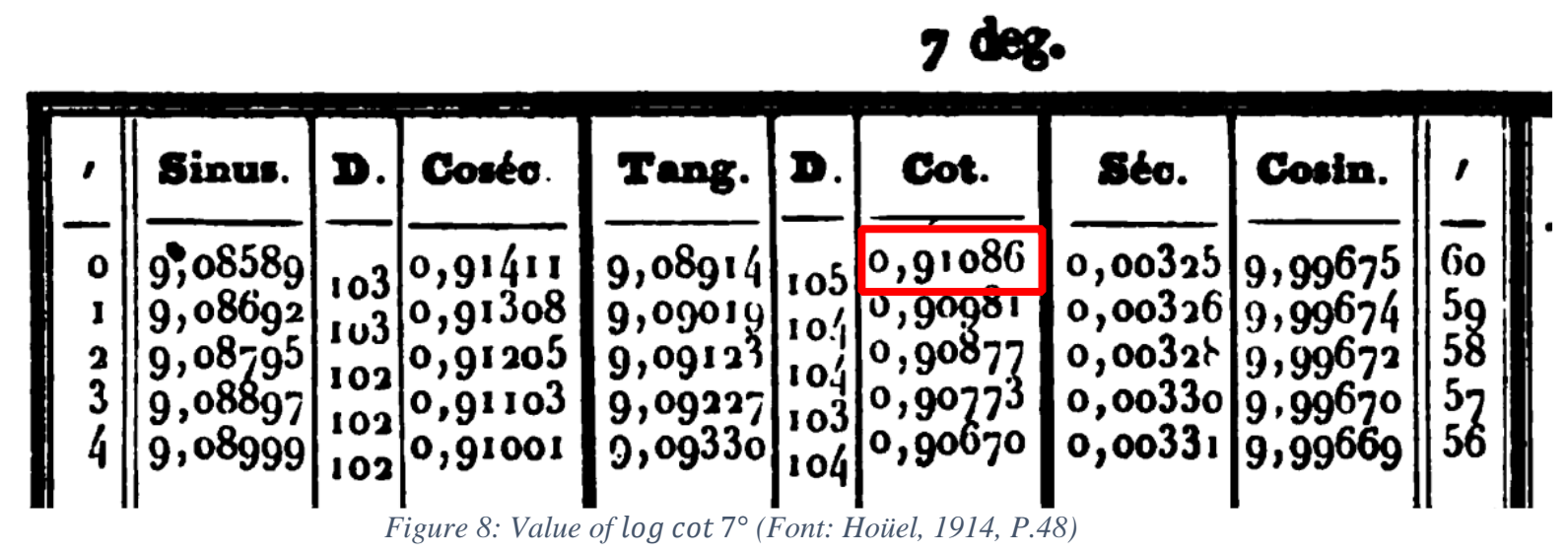

\begin{tabular}{|c|c|c|c|c|c|c|c|c|c|}
\hline 85 & $\begin{array}{l}35 \\
36 \\
37 \\
38 \\
39\end{array}$ & $\left|\begin{array}{l}54407 \\
55630 \\
56820 \\
57978 \\
59106\end{array}\right|$ & \begin{tabular}{r|}
95 \\
96 \\
97 \\
98 \\
99
\end{tabular} & $\left|\begin{array}{l}97772 \\
98227 \\
08677\end{array}\right| \begin{array}{ll}89 & 23 \\
99564\end{array} \mid$ & $\begin{array}{l}155 \\
156 \\
157 \\
158 \\
159\end{array}$ & $\left|\begin{array}{l}19033 \\
19312 \\
19590 \\
19866 \\
20140\end{array}\right|$ & \begin{tabular}{l|l|}
215 & 33244 \\
216 & 33445 \\
217 & 33646 \\
218 & 33846 \\
219 & 34044
\end{tabular} & $\begin{array}{l}275 \\
276 \\
277 \\
278 \\
279\end{array}$ & $\begin{array}{l}43933 \\
44091 \\
44248 \\
44404 \\
44560\end{array}$ \\
\hline 40 & $\begin{array}{l}40 \\
41 \\
42 \\
43 \\
44\end{array}$ & $\left|\begin{array}{l}60206 \\
61278 \\
62325 \\
63347 \\
64345\end{array}\right|$ & $\begin{array}{l}100 \\
101 \\
102 \\
103 \\
104\end{array}$ & $\left|\begin{array}{l}00000 \\
00433 \\
00860 \\
01284 \\
01 \\
01703\end{array}\right|$ & $\begin{array}{l}160 \\
161 \\
162 \\
163 \\
164\end{array}$ & $\mid \begin{array}{l}20413 \\
20683 \\
20952 \\
21219 \\
21484\end{array}$ & \begin{tabular}{l|l|}
220 & 34242 \\
221 & 34439 \\
222 & 34635 \\
223 & 34830 \\
224 & 35025
\end{tabular} & $\begin{array}{l}280 \\
281 \\
282 \\
283 \\
284\end{array}$ & $\begin{array}{l}44716 \\
44871 \\
45025 \\
45179 \\
45332\end{array}$ \\
\hline
\end{tabular}

To conclude, we should observe that for this procedure to be done easily and quickly during the flight, all the necessary tables should be at hand for the navigator. As it was previously emphasized, it was crucial that the navigator could be able to calculate the altitude quickly and efficiently. Therefore, Coutinho had also pre-prepared Hoüel's tables of logarithms by attaching markers at the margins of the relevant pages in order to find the necessary page easily.

"The tables of logarithms, which were those of Hoüel, had also been prepared in such a way that they could be immediately opened on the page necessary, for which they were glued markers at the margin, as the indices of commercial books."4 (Coutinho, 1923, P.17)

4. CONCLUSIONS. Gago Coutinho and Sacadura Cabral successfully completed, for the first time, the First Air Crossing of the South Atlantic from Lisbon to Rio de Janeiro in 1922. In the crossing, they used, for the first time, scientific methods of astronomic navigation. The

4 "As tábuas de logaritmos, que eram as de Hoüel, tinham também sido preparadas de modo a poderem ser abertas imediatamente na folha necessária para o que lhe foram coladas chamadas á margem, como usam os índices dos livros comerciais." (Coutinho, 1923, P.17) 
methods and procedures developed and used were adapted and inspired by the methods used in maritime navigation. However, for these new methods to be used successfully, it was essential to know the approximate value of the aircraft's altitude. The use of the altimeter was not reliable since it gave readings with large errors. Therefore, Coutinho had to conceive a method that allowed the navigator to determine the approximate value of the altitude quickly and efficiently during the flight.

Coutinho's method is based on a mathematical geometrical procedure. This paper aimed to study in detail Coutinho's method to determine the altitude. The paper contains several diagrams so that the reader can easily follow all the mathematical deductions. We conclude our work with a real example of how this method would have been used in a real flight.

Acknowledgements: Teresa Sousa was partially supported by FCT - Fundação para a Ciência e a Tecnologia, Portugal (Portuguese Science Foundation, Portugal), through the project UID/MAT/00297/2019 (Centro de Matemática e Aplicações). The authors thank the anonymous referee for the careful reading of the manuscript.

Remark: All the figures where the font has not been stated where done by the authors.

\section{REFERENCES}

Anonymous (1922). Foreword of the memoir Aerial Navigation. Anais do Clube Militar Naval, 52, 361-362.

Brown, A. W. (1920). Flying the Atlantic in sixteen hours. With a discussion of aircraft in commerce and transportation. Frederick A. Stokes Company.

http://www.gutenberg.org/ebooks/47129

Canas A. C., Marabujo M. and Sousa T. (2019). O corrector de rumos de Gago Coutinho e Sacadura Cabral. Boletim da Sociedade Portuguesa de Matemática. Submitted.

Coutinho, G. and Cabral S. (1922). Aerial Navigation. Anais do Clube Militar Naval, 52, 361389.

Coutinho, G. (1923). Relatório técnico sobre a navegação. Relatórios da $1^{a}$ Travessia Aérea do Atlântico Sul. 1-30.

Coutinho, G. and Cabral S. (1927). A Navegação Aerea. Revista Polytechnica, 8, 384-410.

Hawker, H. G. and Grieve, K. M. M. (1919). Our Atlantic Attempt. London, Methuen \& Company Limited.

https://archive.org/details/ouratlanticattem00hawkrich/page/n8

Hoüel, J. (1914), Tables de Logarithmes a Cinq Décimales pour Les Nombres et les Lignes

Trigonométriques. Gauthier-Villars, Paris.

Jones, B. (1931). Avigation. John Wiley \& Sons, Inc.

Pereira, J. M. (2015). Os Céus de Gago Coutinho e Sacadura Cabral. Memórias 2012, Academia

de Marinha, Lisboa, 42, 263-321.

https://academia.marinha.pt/pt/academiademarinha/Paginas/edicoes.aspx

Wimperis, H. E. (1920). A Primer of Air Navigation. D. Van Nostrand Company, New York. 
https://archive.org/details/aprimerairnavig00wimpgoog/page/n1

Maitland, E. M. (1920). The Log of H. M. A. R34, Journey to America and Back. Hodder and Stoughton Limited, London.

https://archive.org/details/logofhmarjourney00maitrich/page/n5 